\title{
Investigating Correlation and Volatility Transmission among Equity, Gold, Oil and Foreign Exchange
}

\author{
Lukas Hein $^{1}$
}

\begin{abstract}
The paper offers an investigation into the co-movement between the returns of the S\&P 500 stock index, the price of gold, West Texas Intermediate crude oil and the exchange rate of the Swiss Franc to the US Dollar. The research finds significant evidence for a correlation between the returns of the time series as well as their volatilities. The input values for these volatilities is a univariate $\operatorname{GARCH}(1,1)$ process for each of the time series. Are more detailed insight into the correlations is provided by a dynamic conditional correlation model on each pair of assets.

There is enough significant evidence to suggest that the returns are correlated and there is volatility transmission between the assets. Further, the fact that volatility and correlation can be modeled suggests they can also be forecasted. In combination this knowledge is crucial in areas of risk management, portfolio management or even speculation on volatility indices.
\end{abstract}

\section{Introduction}

The consequences of the financial crisis of 2008 clearly demonstrated the high degree of interrelation between different asset classes and financial markets. The increasing integration of markets has led to an unprecedented level of codependence. When subprime lenders started to fail in 2007, the repercussions quickly spread beyond the affected markets, both geographically and categorically (Naoui, Liouane, \& Brahim, 2010). The interbank market, for example, essentially froze due to the fear of the participating banks. The missing confidence signaled by this withdrawal caused the crisis to affect a major part of the economy. This implies that a substantially large positive or negative return in one market seems to be followed by a similar return in another. Such a correlation would of course have significant implications for investors, especially in the presence of a time lag between movements. This would enable investors to anticipate the market reaction in situations of extreme volatility. Even in case of an opposing reaction, the consequences for investors 


\section{Investigating Correlation and Volatility}

would be substantial since it would have a sizeable impact on hedging potential. This paper is aimed at investigating the relation and the spillover between four different asset classes in search of statistical evidence of correlations and volatility transmission between markets.

Composing this paper has numerous motivations. The first is to give a more complete overview of the volatility transmission between equity, gold, oil and foreign exchange than has been done by prior research. Further, there are virtually endless practical applications dependent on the intimate knowledge of how time series interact. Examples of these include, portfolio management, risk management and even public policy.

The rest of this paper is structured as follows. Section 2 provides an overview of the relevant literature on volatility and spillover between financial markets. Section 3 then provides an overview of the methodology used, followed by the empirical findings in Section 4 . Section 5 then concludes.

\section{Theoretical Framework}

The topic of volatility spillover has already been extensively researched in the past. Notable works include Hammoudeh and Yuan's (2008) investigation of oil and interest rate shocks in relation to the volatility of metal commodities. The rationale for expecting volatility transmission between commodities is their dependence on common macroeconomic indicators. Interest also has strong link top commodities, potentially because lower interest rates lead to higher capital expenditure, increasing the demand for commodities. The authors employ different types of models from the $\mathrm{GARCH}$ family in their analyses. The findings provide evidence for a negative impact of oil volatility on metal volatility. In other words, past oil shocks have had a calming effect on gold and silver. The same was found when looking into interest rate volatility. This suggests precious metals provide a sound investment in anticipation of bad times. The results found in their study have far-reaching consequences beyond investment choices. Obvious direct implications apply to using gold as a reserve asset and exporting or producing commodities. Beyond that, derivatives valuations and risk analysis also depend on the relationships between asset classes (Hammoudeh \& Yuan, 2007).

Ewing and Malik (2012) performed a similar investigation into volatility spillover between gold and oil futures, finding strong evidence for transmission of implied volatility when accounting for structural breaks in variance. The importance of oil is readily recognizable due to its omnipresent use in global economies. It is because of its wide utilization that oil 


\section{Investigating Correlation and Volatility}

production, prices and futures have become such closely monitored economic indicators, especially in combination with the general health of the economy. Gold, being a traditional hedge against inflation, is similarly associated with the performance of the economy. The idea of a link between these two commodities is therefore a logical expectation. To demonstrate the practical applicability of these results, they provide an example portfolio with optimal weights and hedge ratios. The authors also stress the importance of the results, not only for investment decisions but for the general economy.

This is closely related to prior work by Narayan, Narayan, and Zheng (2010), which provided empirical evidence for the strong co-integration between gold and oil futures. The findings were used to show that gold prices can be used to predict oil prices and vice versa. This is based on the assumption that rising oil prices create inflationary pressures, which are hedged against through investments in gold. Badshah, Frijns, and Tourani-Rad (2013) transferred this research to equity, gold, and exchange rate volatility. For them, the importance not only lies in finding correlations between asset classes but also the direction of the spillover. The argumentation here is that correlation tests cannot provide evidence of causality. Knowing the direction and size of the spillover effect has a substantial impact on practical implications. Thus, Badshah et al. (2013) employ the "indentification through heteroskedasticity" approach by Rigobon (2003) to track the direction of the spillover. In past literature, researchers often relied on lagged relationships to find transmissions between different assets. The problem with this approach is that simultaneously occurring spillovers are not measured. The "identification through heteroskedasticity" approach bases its parameters on the relationship between the variables observed to identify the asymmetric spillover between the markets. Their results indicate unidirectional transmission from equity to gold and foreign exchange and bi-directional spillover between gold and exchange rate volatility. This means an increase in the volatility index for stocks also leads to an increase in that of gold and exchange rate, while the effect cannot be observed in the other direction. The authors argue that distinguishing between mere correlation and cause and effect has crucial implications for portfolio and risk management. Another important issue to consider is the choice of model. There are, for example, substantial differences between the conclusions supported by different $\mathrm{GARCH}$ models in practical forecasting applications (Kroner, $\mathrm{Ng}, 1998)$.

A somewhat different approach to exploring volatility spillovers was taken by Jiang Konstantinidi and Skiadopoulos (2012), who examined the effect of news announcements in the US and Europe on the spillover of volatility across these markets. The measure of volatility was a set of widely used implied volatility indices. While not all volatility 


\section{Investigating Correlation and Volatility}

transmission is explained in their findings, they do provide evidence of significant influence on the magnitude of volatility spillovers. An interesting finding in the study is the fact that whether or not a news announcement was scheduled has an effect on the change in volatility it causes. Unscheduled news announcements generally increase information uncertainty and therefore lead to higher volatility. Results show the opposite effect for scheduled news announcements (Jiang, Konstantinidi, \& Skiadopoulos, 2012). So clearly, the nature of volatility transmission is one of great interest to the academic world and has been thoroughly researched.

This paper goes beyond the scope of previous research by investigating a more extensive time period, namely all daily closing prices from 1990 to 2013. With this considerably longer time period, the data should provide more situations of extreme volatility than just the most recent crisis. Further, the scope is broadened by including four major asset classes, namely equity, gold, oil, and foreign exchange. This combines the efforts of the above mentioned articles to form a complete picture of the relation and the spillover between four major asset classes. The research question is therefore: How do periods of abnormal volatility in a specific asset affect the returns of another? The question essentially holds two aspects which need to be covered in order to find an answer. Firstly, the question of how the four instruments tend to move over time and in relation to each other and, secondly, to what extent volatility changes are transferred across them. Accordingly, the hypotheses for investigation become:

$\mathrm{H} 1$ : There are significant correlations between the returns of at least two of the assets.

$\mathrm{H} 2$ : There are significant correlations between the volatilities of at least two of the assets.

\section{Methodology}

To test the behavior of each asset class efficiently, four time series were chosen so as to represent the behavior of each class as precisely as possible. The four instruments equity, precious metals, commodities and foreign exchange were thus chosen as the Standard \& Poor's 500 index, gold, West Texas Intermediate Oil and the CHF/USD exchange rate. All four time series were acquired from the Reuters Datastream database for the period between Jan 11990 and Dec 31 2013. However, since the representativeness of the four assets is beyond the scope of this paper, the results cannot be generalized beyond the four time series. 


\section{Investigating Correlation and Volatility}

Figure 1 shows the daily returns of each of the assets. Visually, the diagrams do not provide any evidence of a serial correlation in the returns. There does, however, seem to be a correlation in their magnitude. In other words, the figure shows clusters of similar returns. Large changes of either direction seem to be followed by other large changes. The same goes for periods of low positive or negative returns. A more detailed depiction of each asset's return distribution can be found in the appendix, together with the autocorrelation and pacf plots. All distributions are close to symmetrical and are centered near the mean (see Appendix A1). The $Q Q$ plots of the returns show an inverted "s-shape" for each of the series, implying heavy tails. This essentially means that extreme returns are more likely to occur than they would be in a standard normal distribution. To confirm this, a normality test was performed using the Jarque-Bera Test (Jarque \& Bera, 1980) for normality, which rejected the null hypothesis of a normal distribution.
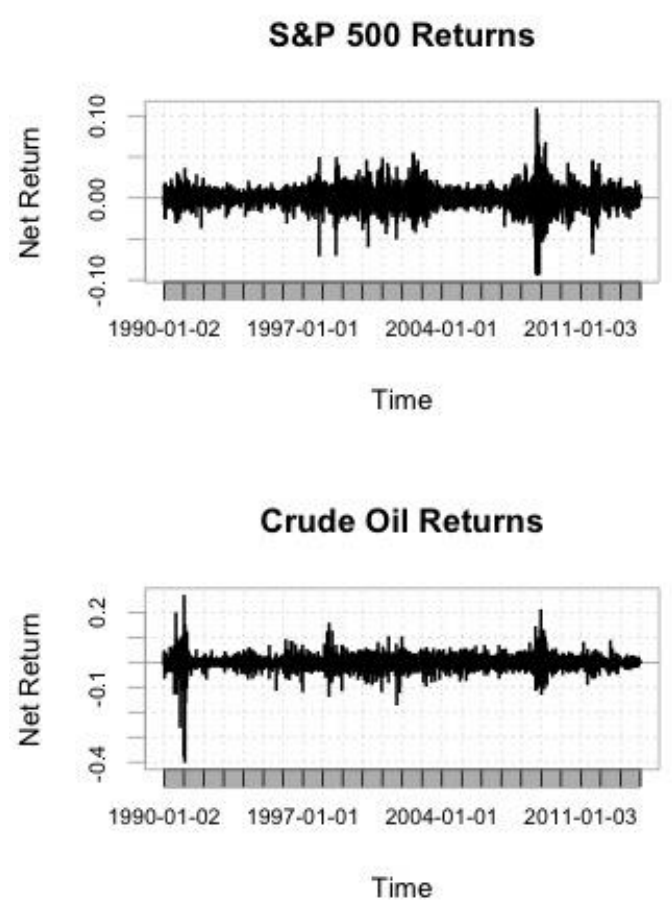
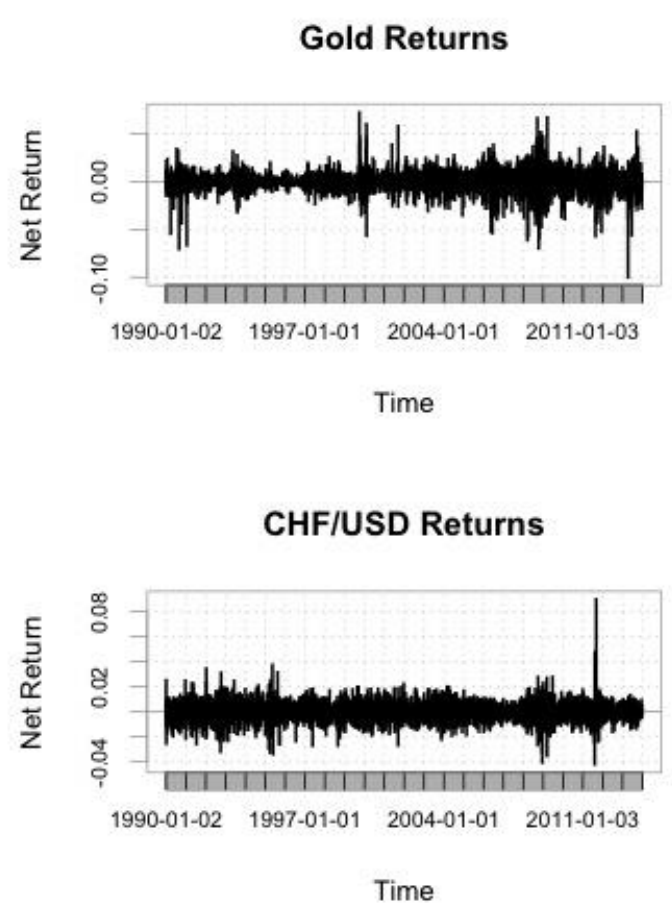

Figure 1 Daily Returns of the Time Series

Since a major objective of this research is the investigation of volatility transmission between the asset classes, modeling volatility plays a rather prominent role. This is achieved by fitting a $\operatorname{GARCH}(1,1)$ process to each of the time series. The fitted values are then used as inputs for the correlation analyses. The model is a generalization of the autoregressive conditional heteroskedasticity $(\mathrm{ARCH})$ model (Bollerslev, 1986). The basic GARCH process is defined as shown in equation 1 (Diebold, 2006): 


$$
\begin{gathered}
\gamma_{t}=\varepsilon_{t} \\
\varepsilon_{t} \mid \Omega_{t-1} \sim N\left(0, \sigma_{t}^{2}\right) \\
\sigma_{t}^{2}=\omega+\alpha(L) \varepsilon_{t}^{2}+\beta(L) \sigma_{t}^{2} \\
\alpha(L)=\sum_{i=1}^{p} \alpha_{i} L^{i}, \quad \beta(L)=\sum_{i=1}^{q} \beta_{i} L^{i} \\
\omega>0, \quad \alpha_{i} \geq 0, \quad \beta_{i} \geq 0, \quad \sum \alpha_{i}+\sum \beta_{i}<1
\end{gathered}
$$

Here, the error term $\varepsilon_{\mathrm{t}}$ represents strong white noise, which is independent and identically distributed with mean zero. A more detailed explanation of the model's parameters will follow in Section 4. This research implements a univariate GARCH process to model the volatility of the four investigated time series. As mentioned earlier, the return plots show volatility clustering, which can be a sign for a correlation in the squares of returns. Based on this dependence, one can make the assumption that return magnitude can be at least partially forecasted (Bollerslev, 1986).

An initial and rather straightforward way of examining the relationship between the four time series is to run correlation tests on them. This is done on both the simple daily returns and the fitted values of the GARCH model, as a proxy for volatility. As mentioned earlier, using correlations no evidence on the direction of contemporaneous spillovers can be found. Since this is not an aim of this paper, however, correlations present a valid choice. Further, the correlations are tested when incorporating a time lag between the two measured series. In combination, these two forms of correlation analysis provide a decent overview over the coordinated behavior of the time series.

As both hypotheses aim to investigate the correlational behavior of aspects of the four time series, a further key component of this paper is the estimation of a multivariate dynamic conditional correlation GARCH model as proposed by Engle (2002) to the time series. The DCC-GARCH is an extension of the constant conditional correlation model (Bollerslev, 1990) in that it allows the conditional correlation to vary over time, while providing less complexity than multivariate $\mathrm{GARCH}$ processes. The inputs to the model in this case are the parameters of the univariate GARCH estimation described earlier.

All of the above analyses are repeated for weekly data. The time series for this were attained by simply using the weekly average of the daily closing prices for the S\&P 500, gold, crude oil, and currency used before. 


\section{Investigating Correlation and Volatility}

\section{Empirical Findings}

As described in the methodology section, the common movement of asset returns was initially tested using simple correlation. Table 1 below shows the correlation matrix between the daily returns of the S\&P 500, Gold, West Texas Intermediate Oil and the CHF/USD exchange rate. As can be seen, all results are significant, with the correlation between equity and gold having a p-value below 0.01 and all others below 0.001 . Despite the high significance of the results, their actual correlations are rather modest. An explanation for this that readily comes to mind is the large number of influences on each of the assets.

\section{Table 1 Correlation among daily returns}

\begin{tabular}{lcccc} 
Correlation Matrix & & & \\
\hline & SP500 & Gold & Crudoil & CHFUSD \\
\hline SP500 & & & & \\
Gold & $-0.04^{* *}$ & & & \\
Crudoil & $0.07^{* * *}$ & $0.16^{* * *}$ & & \\
CHFUSD & $0.10^{* * *}$ & $-0.23^{* * *}$ & $-0.07^{* * *}$ & \\
\hline
\end{tabular}

The negative correlation between Gold and the S\&P 500 was to be expected, since gold is generally viewed as a sound investment in case of an economic downturn (Hammoudeh \& Yuan, 2007).

The results of the GARCH estimation were similarly significant. Table 2 shows the coefficients which were obtained by fitting a univariate $\mathrm{GARCH}$ model to each of the processes. All values are highly significant with a p-value below 0.001 , except for the mu of Gold, Crude Oil, and CHF/USD, which were insignificant. All assets show a very high volatility persistence. This is represented by the sum of alpha and beta and can be interpreted as the rate of decay after a volatility shock. The amount of such a shock, which feeds through to the next period is measured by alpha (Campbell, Lo, \& MacKinlay, 1996). The assets' persistence is therefore 0.992 for equity, 1 for Gold, 0.996 for Crude Oil, and 0.991 for CHF/USD. A volatility persistence of 1 , like in the case of Gold, means today's volatility theoretically has an unlimited impact into the future (Campbell, Lo, \& MacKinlay, 1996). Ewing and Malik (2013) found, however, that this high persistence, although consistent with prior research, is largely due to a failure to account for structural breaks. Their data shows that the half-life of volatility shocks sharply drops to only a few days after accounting for structural breaks. In general, the results are largely in line with Ewing and Malik (2013). The full output of the GARCH estimation can be found in the appendix. 


\section{Investigating Correlation and Volatility}

Figure 2 below shows a visual representation of the volatility estimates provided by the $\operatorname{GARCH}(1,1)$ model for each of the examined assets. The general shape of the models is what was to be expected. All four time series collectively show a spike in volatility during the financial crisis of 2008 and independently in their own periods of turmoil. The volatility of crude oil, for instance, exhibits a sharp increase in volatility between 1990 and 1991 during the time of the Gulf War. Similarly, the S\&P 500 shows several periods of abnormal volatility during the times of the dot-com bubble, September $11^{\text {th }}$, and the war in Iraq. The Swiss Franc to US Dollar exchange rate also shows a peak in estimated volatility during the European Debt crisis. All in all, the plots provide a helpful visual aid for evaluating the $\mathrm{GARCH}(1,1)$ models and generally coincide with the broad expectations about volatility in the past 23 years.

Using the fitted values which were obtained from the above models, one can now test the correlation between the volatilities of each of the models. The results were much less statistically significant than those concerning the daily return series. Only the correlation of the S\&P 500 with Gold and CHF/USD were significant with a p-value below 0.001 . The correlations other than that of crude oil and gold have a $5 \%$ significance level. Just like in the daily returns, however, the correlations were quite weak.

The use of simple correlations in this case is rather limited though. Throughout the time period between 1990 and 2013, the time series have gone through periods of abnormally large positive and negative returns. Since the time series have changed so much in the sample period, it is not very useful to employ a constant correlation. The much more advisable approach lies in the fitting of a DCC-GARCH. 

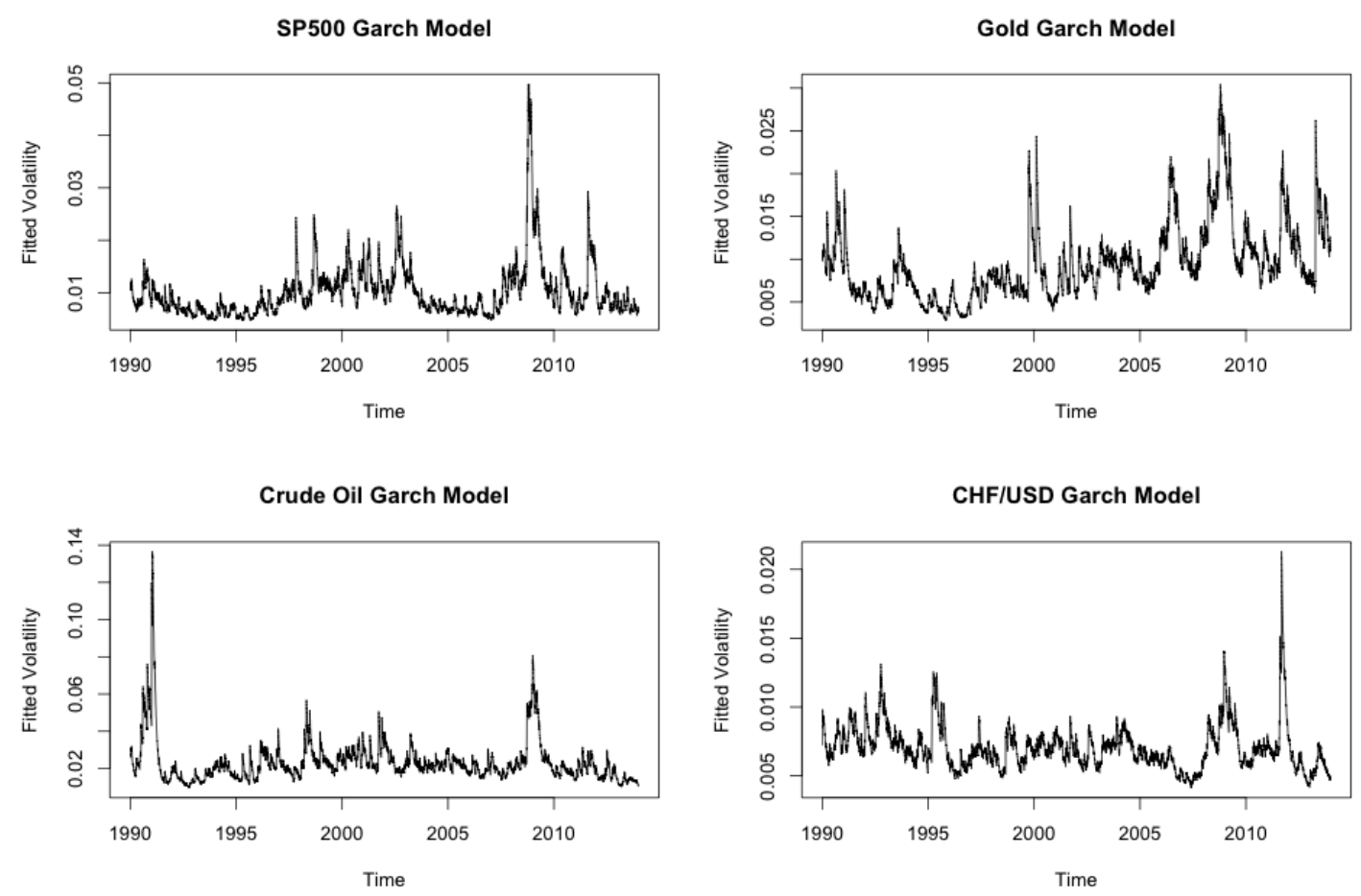

Figure 2 Plotted univariate GARCH models for each time series

GARCH(1,1) Coefficients

\begin{tabular}{lllll}
\hline & SP500 & Gold & Crudoil & \multicolumn{1}{l}{ CHFUSD } \\
\hline mu & 0.00051887 & -0.00003368 & 0.00019771 & -0.00010078 \\
omega & 0.00000096 & 0.00000025 & 0.00000320 & 0.00000040 \\
alpha & 0.07012188 & 0.05415638 & 0.06155468 & 0.03680356 \\
beta & 0.92192280 & 0.94720377 & 0.93585596 & 0.95565090 \\
\hline
\end{tabular}

Table 2 Coefficients from the $\operatorname{GARCH}(1,1)$ estimation

\begin{tabular}{|c|c|c|c|c|}
\hline & SP500 & Gold & Crudoil & CHFUSD \\
\hline \multicolumn{5}{|l|}{ SP500 } \\
\hline Gold & $0.05 * * *$ & & & \\
\hline Crudoil & $-0.03^{*}$ & 0.00 & & \\
\hline CHFUSD & $-0.03 * * *$ & $-0.03^{*}$ & $-0.03^{*}$ & \\
\hline
\end{tabular}

Table 3 Correlations among fitted $\mathrm{GARCH}(1,1)$ values

Figure 3 shows the plotted estimations from the dynamic conditional correlation model. The first notable quality is the high amount of change in correlation between each pair of assets throughout the investigated time period. This is another indication that the simple 


\section{Investigating Correlation and Volatility}

correlations performed earlier are simply not powerful enough to provide a complete picture of the interaction between the time series. It is evident from the plots, that practical applications should not be based on static correlations between assets. Table 4 shows the actual output and the respective standard errors of the DCC-GARCH between each pair of the time series.
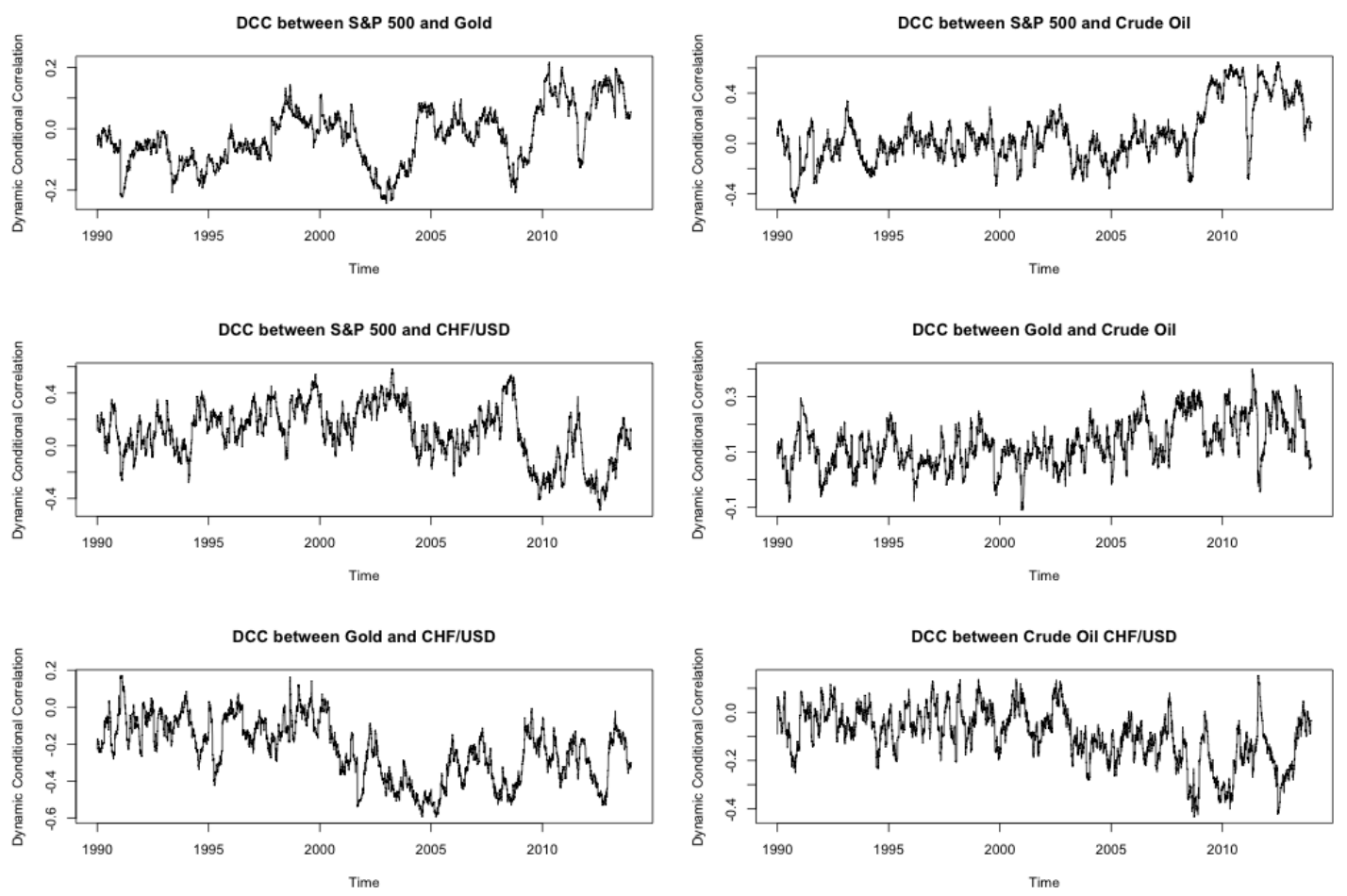

Figure 3 Plotted DCC-GARCH estimates between all time series

An interesting observation to make is that the correlation between S\&P 500 and Gold becomes strongly negative during the financial crisis of 2008 , as was to be expected. This provides evidence of gold being seen as a safe haven during times of crisis (Ewing \& Mailk, 2012). Plotting Volatility against DCC (Figure 4) supports this statement. Figure 4 also shows that this is not only true for the crisis of 2008. It can be observed that every abnormal increase in equity volatility is met by a stronger negative correlation between the S\&P 500 and the price of gold. Referring back to Figure 2, one can also find evidence for the statement made by Ewing and Malik (2013), a link between gold and oil. The authors make the claim that higher oil prices lead to generally higher price levels, which investors tend to hedge against using gold. The generally positive estimates between gold and oil and the negative estimates between gold and CHF/USD provide supporting evidence for this statement. 
DCC-GARCH SP500 and Gold

\begin{tabular}{lrrrrrrrr}
\hline \multicolumn{1}{l}{ a1 } & a2 & \multicolumn{2}{c}{ A11 } & A22 & \multicolumn{1}{c}{ B11 } & B22 & \multicolumn{1}{c}{ dcc alpha } & dcc beta \\
\hline estimates & $9.56 \mathrm{E}-07$ & $2.51 \mathrm{E}-07$ & 0.070121878 & 0.05415638 & 0.9219228 & 0.947203771 & 0.006763005 & 0.990159726 \\
std.err & $2.43 \mathrm{E}-07$ & 0.008289724 & 0.007816452 & $8.60 \mathrm{E}-08$ & 0.010723287 & 0.009211157 & 0.0058936 & 0.009322264 \\
\hline
\end{tabular}

DCC-GARCH SP500 and Crude Oil

\begin{tabular}{lrrrrrrrr} 
& a1 & a2 & \multicolumn{1}{c}{ A11 } & A22 & \multicolumn{1}{c}{ B11 } & B22 & dcc alpha & dcc beta \\
\hline estimates & $9.56 \mathrm{E}-07$ & $3.20 \mathrm{E}-06$ & 0.070121878 & 0.061554677 & 0.9219228 & 0.935855957 & 0.021269653 & 0.975159631 \\
std.err & $2.43 \mathrm{E}-07$ & 0.008289724 & 0.007816452 & $1.39 \mathrm{E}-06$ & 0.008138841 & 0.009133219 & 0.015019207 & 0.01699765 \\
\hline
\end{tabular}

DCC-GARCH SP500 and CHF/USD

\begin{tabular}{lllllllll}
\hline & a1 & a2 & A11 & A22 & B11 & B22 & dcc alpha & dcc beta \\
\hline estimates & $9.56 \mathrm{E}-07$ & $4.04 \mathrm{E}-07$ & 0.070121878 & 0.036803563 & 0.9219228 & 0.9556509 & 0.022456434 & 0.971684015
\end{tabular}

\begin{tabular}{llllllllll} 
std.err & $2.43 \mathrm{E}-07$ & 0.008289724 & 0.007816452 & $1.21 \mathrm{E}-07$ & 0.006324647 & 0.006606653 & 0.020111874 & 0.02564414 \\
\hline
\end{tabular}

DCC-GARCH Gold and Crude Oil

\begin{tabular}{|c|c|c|c|c|c|c|c|c|}
\hline & a1 & $a 2$ & A11 & A22 & B11 & B22 & dcc alpha & dcc beta \\
\hline & 2.51E-07 & -06 & 5638 & 61554677 & 203771 & 5855957 & 5401 & 782616 \\
\hline std & 8.60E-08 & 0.010723287 & 0.009211157 & $1.39 \mathrm{E}-06$ & 0.008138841 & 0.009133219 & 0.008590413 & 0.016550183 \\
\hline
\end{tabular}

DCC-GARCH Gold and CHF/USD

\begin{tabular}{lllllllll}
\hline & a1 & a2 & A11 & A22 & B11 & B22 & dcc alpha & dcc beta \\
\hline estimates & $2.51 \mathrm{E}-07$ & $4.04 \mathrm{E}-07$ & 0.05415638 & 0.036803563 & 0.947203771 & 0.9556509 & 0.016734458 & 0.978951869
\end{tabular}

\begin{tabular}{lllllllll} 
std.err & $8.60 \mathrm{E}-08$ & 0.010723287 & 0.009211157 & $1.21 \mathrm{E}-07$ & 0.006324647 & 0.006606653 & 0.020321066 & 0.025825895 \\
\hline
\end{tabular}

DCC-GARCH Crude Oil and CHF/USD

\begin{tabular}{llrrrrrrr}
\hline \multicolumn{2}{c}{ a1 } & a2 & \multicolumn{1}{c}{ A11 } & A22 & \multicolumn{1}{c}{ B11 } & \multicolumn{1}{c}{ B22 } & \multicolumn{1}{c}{ dcc alpha } & dcc beta \\
\hline estimates & $3.20 \mathrm{E}-06$ & $4.04 \mathrm{E}-07$ & 0.061554677 & 0.036803563 & 0.935855957 & 0.9556509 & 0.015115918 & 0.975874972 \\
std.err & $1.39 \mathrm{E}-06$ & 0.008138841 & 0.009133219 & $1.21 \mathrm{E}-07$ & 0.006324647 & 0.006606653 & 0.008940514 & 0.014888444 \\
\hline
\end{tabular}

Table 4 Parameter estimates and standard errors of DCC-GARCH estimations

S\&P 500 Volatility and S\&P 500 Gold Correlation Estimates

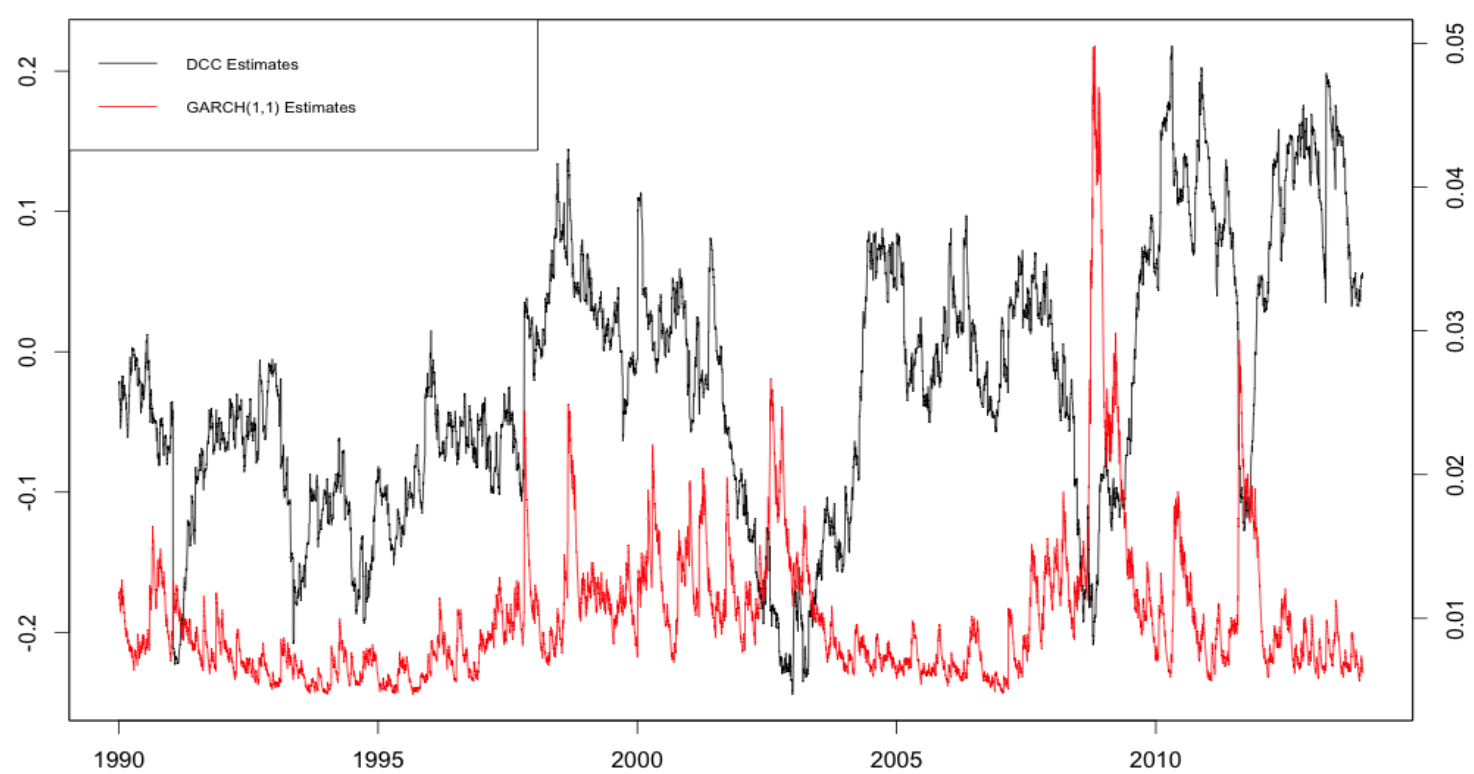

Figure 4 Plotted estimates of the S\&P 500 GARCH process in combination with DCC model of S\&P 500 and Gold 


\section{Investigating Correlation and Volatility}

Repeating the analyses for the weekly average prices yielded similar results. It appears as though the weekly returns are much closer to a normal distribution, albeit still with slightly heavy tails. Running the Jarque-Bera test for normality on the returns, however, provides significant evidence against a normal distribution in any of the time series.

Testing for correlations again shows that there are significant correlations present among the return series. As shown in Table 5, gold is significantly correlated with crude oil and the Swiss Franc to US Dollar exchange rate. Further, the S\&P 500 is correlated with crude oil at the 0.001 significance level and with CHF/USD at the 0.05 significance level. CHF/USD is also correlated with West Texas Intermediate with a p-value of 0.01 .

\section{Table 5 Correlation of weekly returns}

\begin{tabular}{lllll}
\multicolumn{4}{l}{ Weekly Return Correlations } \\
\hline & SP500 & Gold & Crudoil & CHFUSD \\
\hline SP500 & & & & \\
Gold & 0.02 & & & \\
Crudoil & $0.11^{* * *}$ & $0.23^{* * *}$ & \\
CHFUSD & $0.07^{*}$ & $-0.31^{* * *}$ & $-0.08^{* *}$ & \\
\hline
\end{tabular}

Just as for the daily return data, a $\operatorname{GARCH}(1,1)$ process was fitted to the time series in order to model volatility. Figure 6 below shows a plot of the estimations for each the assets. Compared to the GARCH models of the daily returns discussed earlier, the general shape of the weekly volatility is almost identical. In general, weekly volatility is just slightly higher. The only notable difference lies in the crude oil returns. The peak in 1991 is lower in the weekly data while that of 2008 is higher, as compared to the daily time series.

Finally, also the weekly returns were subjected to the estimation of a dynamic conditional correlation model. The plotted values can be seen in Figure 7. As with the $\operatorname{GARCH}(1,1)$ values, the graphs are largely similar. 

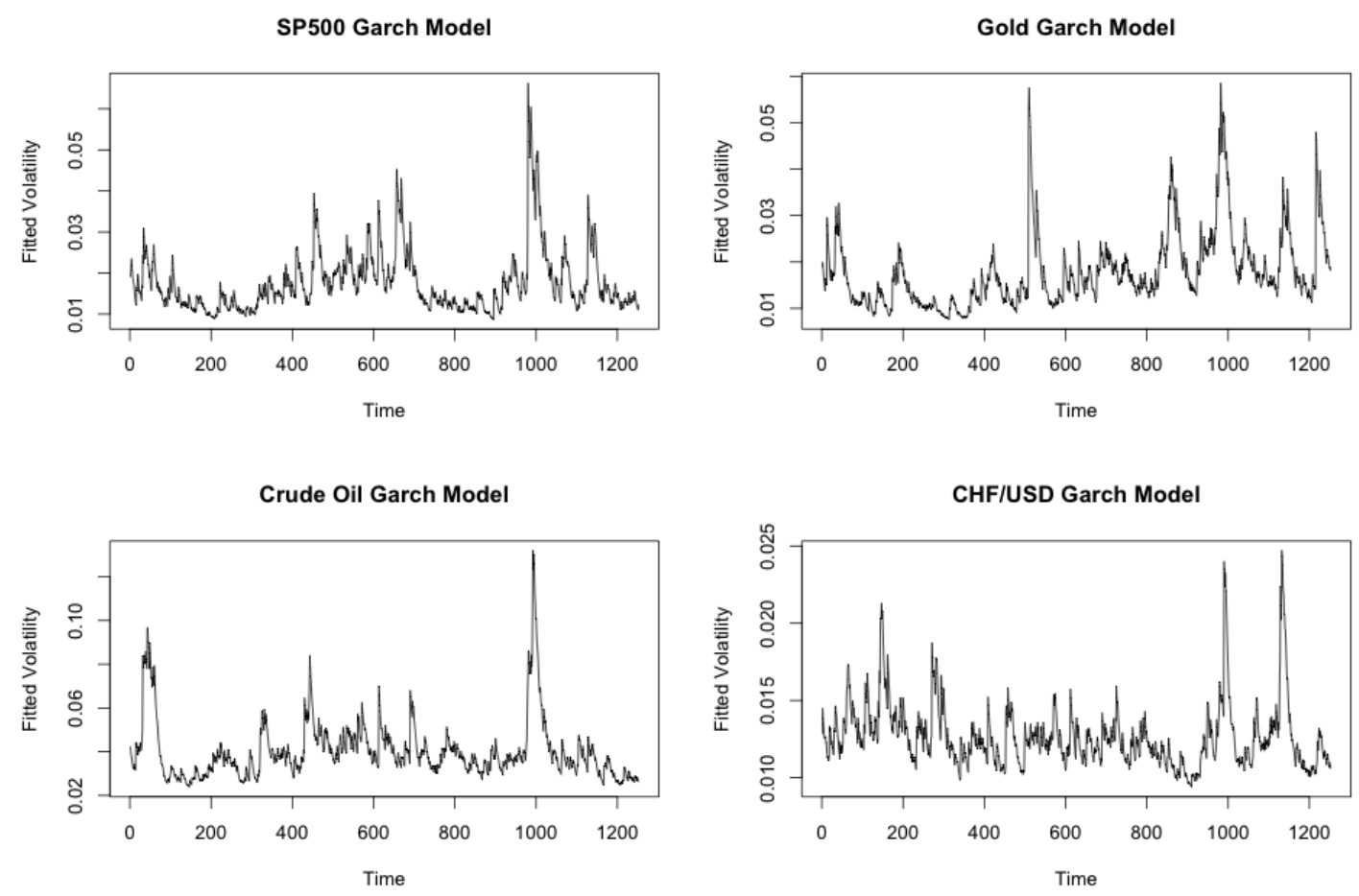

Figure 6 GARCH models of weekly return data
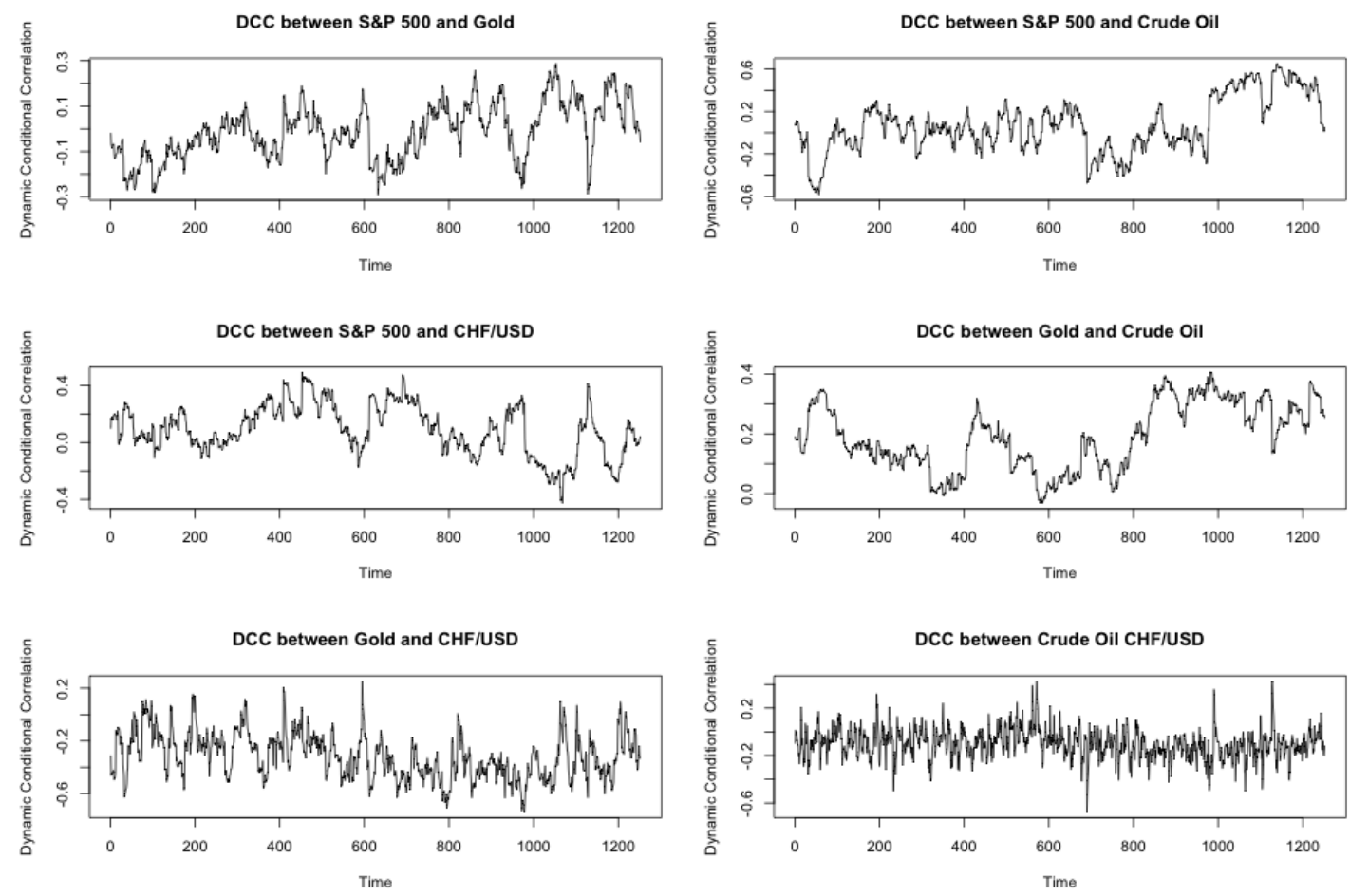

Figure 7 DCC-GARCH of weekly returns 


\section{Investigating Correlation and Volatility}

\section{Conclusion}

Ultimately, the paper offered an investigation into the co-movement between the returns of the S\&P 500 stock index, the price of gold, West Texas Intermediate crude oil and the exchange rate of the Swiss Franc to the US Dollar. The research found significant evidence for a correlation between the returns of the time series as well as their volatilities. The input values for these volatilities was a univariate $\operatorname{GARCH}(1,1)$ process for each of the time series. Are more detailed insight into the correlations was provided by a dynamic conditional correlation model on each pair of assets. Everything was then repeated with weekly data.

Concerning, the initial hypotheses, there was enough significant evidence to reject the null hypothesis in both cases. This means that the returns are correlated and there is volatility transmission between the assets. Further, the fact that volatility and correlation can be modeled suggests they can also be forecasted. In combination this knowledge in crucial in areas of risk management, portfolio management or even speculation on volatility indices. 


\section{Investigating Correlation and Volatility}

\section{References}

Badshah, I., Frijns, B., \& Tourani-Rad, A. (2013). Contemporaneous Spill-Over Among Equity, Gold, and Exchange Rate Implied Volatility Indices. Auchland: Wiley Periodicals.

Bollerslev, T. (1986). General Autoregressive Conditional Heteroskedasticity. Journal of Econometrics , 307-327.

Bollerslev, T. (1990). Modeling the coherence in short-run nominal exchange rates: A multivariate generalized ARCH approach. Review of Economics and Statistics , 498505.

Campbell, J. Y., Lo, A. W., \& MacKinlay, A. C. (1996). The Econometrics of Financial Markets. Princeton: Princeton University Press.

Diebold, F. X. (2006). Elements of Forecasting. Mason: Thomson South-Western.

Engle, R. (2002). Dynamic Conditional Correlation: A Simple Class of Multivariate Generalized Autoregressive Conditional Heteroskedasticity Models. San Diego: Journal of Business Economics \& Statistics.

Ewing, B., \& Mailk, F. (2012). Volatility transmission between gold and oil futures under structural breaks. Elsevier.

Hammoudeh, S., \& Yuan, Y. (2007). Metal volatility in presence of oil and interest rate shocks. Philadelphia: Elsevier.

Jarque, C. M., \& Bera, A. K. (1980). Efficient Tests for Normality, Homoskedasticity, and Serial Independence of Regression Residuals. Economic Letters , 255-259.

Jiang, G., Konstantinidi, E., \& Skiadopoulos, G. (2012). Volatility spillovers and the effect of news announcements. Elsevier.

Naoui, K., Liouane, N., \& Brahim, S. (2010). A Dynamic Conditional Correlation Analysis of Financial Contagion: The Case of the Subprime Credit Crisis . International Journal of Economics and Finance, 85-96.

Rigobon, R. (2003). Identification through Heteroskedasticity. The Review of Economics Studies, 777-792. 